\title{
Control of Low-Frequency Oscillation on Electrical Power System Under Large EV-Charging Station Installation Using PSO Technique for Turning PSS Parameters
}

\author{
Kulsomsup Yenchamchalit ${ }^{1}$, Yuttana Kongjeen ${ }^{2}$, Krischonme Bhumkittipich ${ }^{1}$, \\ Andrei Stativa $^{3}$, Nadarajah Mithulananthan ${ }^{4}$
}

\begin{abstract}
This paper presents a low-frequency oscillation compensation in an electrical power system connecting large-scale electric vehicle loads (EVs). The Particle Swarm Optimization (PSO) method has been adapted to adjust the control parameters of the generator under Power System Stabilizer (PSS) parameters. The EVs charging stations have been directly installed to the power grid for the battery charging process of the EVs according to the increasing number of EVs. The DC fast charging of the large scale EVs has been significantly affected by the low-frequency oscillation of the grids that have been considered in terms of power system stability margin. This paper has aimed to solve the methodology for turning the PSS parameters by adapting the PSO via $M A T L A B^{\circledR}$ and DIgSILENT ${ }^{\circledR}$. The PSS could control the low-frequency oscillation in the proposed power grids. The simulation system has selected the 6-bus testing system, which has increased the EVs loads by 50,100, 150, 200, and 300 percentages at bus No. B3. The simulation results have indicated that the rotor low-frequency oscillation could control instability region. Therefore, the proposed PSS controller turning could handle the power system swing and adjust the power system stability. In this condition, the proposed PSO method should have been explicitly used for low-frequency swing control of the generator's rotor into a balanced state under the large-scale EVs penetration level. Copyright (C) 2021 The Authors.

Published by Praise Worthy Prize S.r.l. This article is open access published under the CC BY-NC-ND license (http://creativecommons.org/licenses/by-nc-nd/3.0/).
\end{abstract}

Keywords: DC Fast Charging, Electric Vehicle Load, Power System Stabilizer, Particle Swarm Optimization, Power System Stability, V2G

\section{Nomenclature}

$T_{e}$

$T_{m}$

$T_{a}$

$(J)$

$a P$

$b P$

$c P$

$a Q$

$b Q$

$c Q$

$V_{0}$

V

$\omega$

$\sigma$

AVR

PSS

PSO

EVs

ZIP

VDL

SMIB
Electrical torque

Mechanical torque

Accelerating torque

Initial inertia

Active parameters phase a

Active parameters phase $b$

Active parameters phase $c$

Reactive parameters phase a

Reactive parameters phase $b$

Reactive parameters phase $\mathrm{c}$

Nominal voltage

Operation voltage

Oscillation frequency

Swing delay

Automatic Voltage Regulator

Power System Stabilizer

Particle Swarm Optimization

Electric Vehicle Loads

One type of voltage-dependent load

Voltage-Dependent Load

Single Machine Infinite Bus

$\begin{array}{ll}\zeta & \text { Maximum damping ratio function } \\ f & \text { Frequency of swing } \\ \left(K_{P S S}, T_{1}, T_{2}, T_{3}, T_{4}\right) & \text { Number variable } \\ \left(T_{W}\right) & \text { Time constant of the washout filter } \\ \left(c_{1}, c_{2}\right) & \text { Weight of velocity of particle } \\ & \text { swarm } \\ \left(T_{U}, T_{L}\right) & \text { Time constant upper-lower value } \\ (N) & \text { Particle number } \\ (i) & \text { Maximum iteration }\end{array}$

\section{Introduction}

Electric Vehicles (EVs) have become of critical interest in the new technology vehicles used to travel and transfer passengers. Manufacturers have developed EVs in order to meet the increasing demand in many countries, with government support throughout each national policy [1]. The EVs yield has a good relationship with low environmental impact such as air pollution and zero carbon emission. EVs could significantly save the world in the long run. However, car users' behavior is interested in new car technology with many types of EVs technology. The advanced electronic 
power and material technology are made to support the growth of the EVs technology. The uncertainty that leads many people to worry about the use of electric vehicles has been reducing in terms of positive way of rapid high technology growth. If they use EVs, it should mean that the energy can be recharged anywhere so that the EVs can be used anywhere, anytime, including normal/quick charger plugs. EVs can be plugged into any standard home light, which takes about 5-8 hours to charge fully the battery. The normal AC charger installed in an office building or a shopping mall takes about 2-3 hours to charge fully the battery. At the same time, a DC Quick charger installed in a charging station takes about 30 minutes to charge fully the battery [2]. Many researchers are interested in studying numerous experiments; motor technology, traction motor driving and control, energy storage system, battery technology, and charging station affecting the power system. Fig. 1 shows a smart energy management network supporting next transportation and next power system planning [3]. The battery energy storage system used to drive the EV has been obtained from the energy accumulated in the battery through the charging station. Therefore, the dynamic behavior of EVs has revealed a bi-directional characteristic in charging and discharging modes to the power grid on the AC charging model and the DC quick charging model. Meanwhile, Vehicle-to-Grid (V2G) has been considered to control low-frequency droop and scheduled charging, affecting the frequency fluctuation from the different types of EV charging demands [4]. The impact of the EVs on different voltage droop load models and the chargers have been discussed in terms of charging duration; as time has increased, grid losses, and grid voltage, whose voltage deviations had caused an impact, have been described in [5]. The EVs battery charging demand needs to be analyzed and investigated in terms of any uncertain pattern of EVs load in the electrical power system relevant to an agent-based approach [6].

Consequently, EVs can reduce the impact from charging mode simultaneously or in the same power transmission line by using $\mathrm{V} 2 \mathrm{G}$ technology and in combination with smart grid control [7]. The smart grid concept is needed to manage the relevant areas in the optimal condition, such as power system substation, power transmission system, power distribution system, end-user benefits, and energy economics [8]. Moreover, a fast-charging station in urban-dwelling areas can be affected by the electrical power system under voltage drop conditions, transmission line loading, transformer loading, peak demand, and increase of total power loss [9]. Therefore, the electrical power system needs to be managed in order to reduce the factors limiting its capacity to provide sufficient energy.

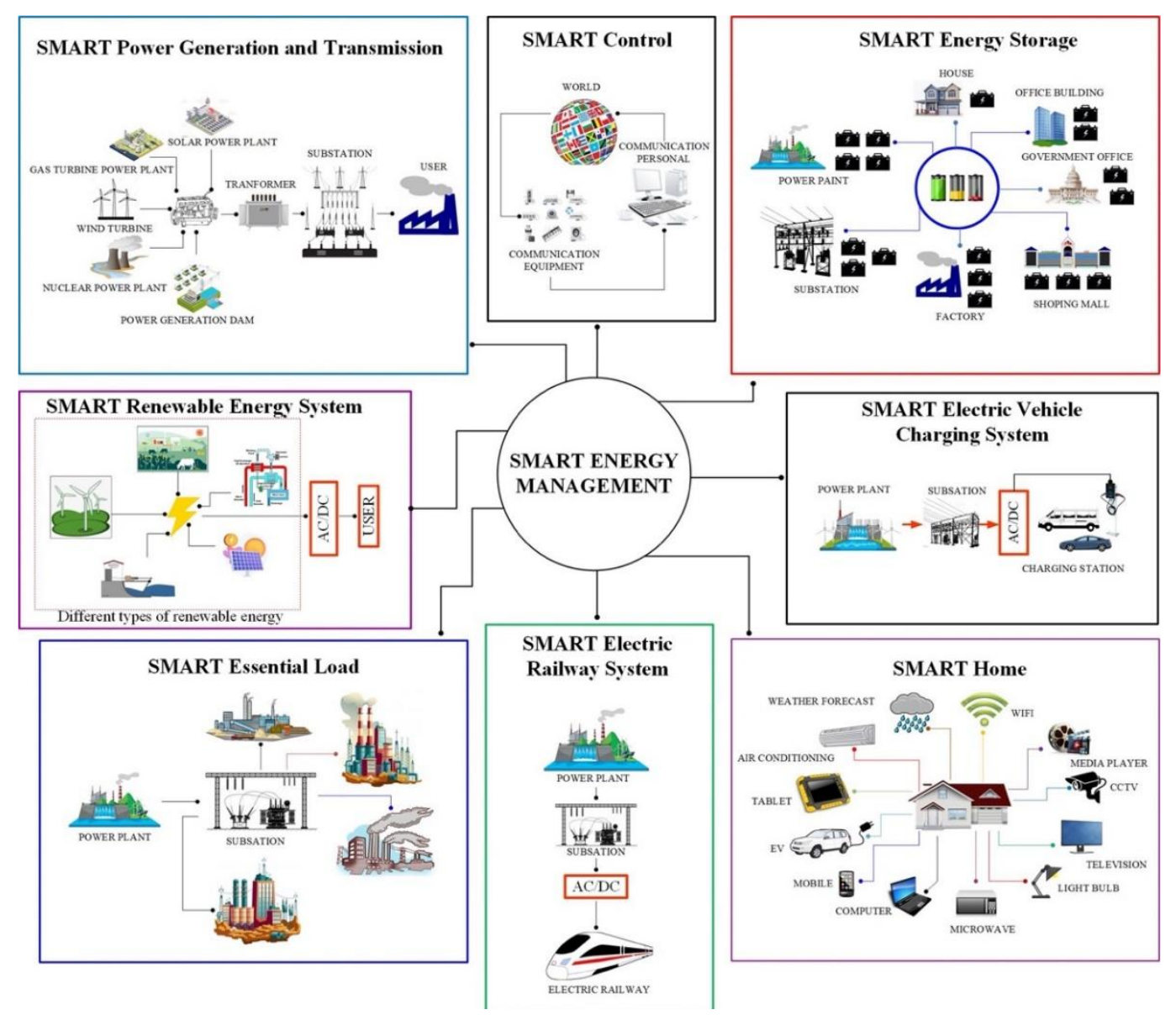

Fig. 1. Smart energy management network for next power system 
The EVs charging station and the battery energy system have modeled the active/reactive power source, the constant power demand load for normal electrical load, the AC/DC Voltage Source Converter (VSC), and the three special loads, namely, Voltage-Dependent Load (VDL), exponential load model, and ZIP load [10]-[12].

Fig. 2 shows the 6-bus testing system under different EV penetration levels. The EVs load modeling is defined in many load types: power constant $(\mathrm{P})$, current constant (I), polynomial load or ZIP load, and voltage source converter modeling. This article has investigated the previous literature, which has used several techniques depending on the best system performance and sufficient conditions. The optimization technique is used to determine the optimal condition from the max/min objective function and equality and inequality constraints. The objective function can be selected under the maximum or the minimum requirement, classified into two types, with single- and multi-objective functions. The equality and the inequality constraints are also defined under the limitation and the boundary conditions of the proposed system. Artificial intelligence, for example, Genetic Algorithm (GA), Ant Colony Optimization (ACO), Gray Wolf Optimization (GWO), and Particle Swarm Optimization (PSO) are also optimization techniques proposed to be studied in this area. The results obtained by comparing these methods have showed that the efficiency of the particle cluster optimization method is more capable than the other three methods [13]-[16]. The solution of multiple path pairs and the complex calculations have been expressed to find the optimal condition based on the PSO simulation and other optimization techniques. The optimal path pair with Rated Gross Weight (RGW) is a criterion with higher priority, considering that the simulation results showed the best performance. Therefore, PSO technique has been chosen to control the Power System Stabilizer (PSS) parameters, which could be controlled by the lowfrequency oscillations [17].

The rest of this paper is organized as follows. Section II presents the analysis of the power system stability and the types of proposed EVs loads consisting of power system swing theory, power system stabilizer, the particle swarm optimization technique, ZIP load as EVs load, and the damping ratio of the power system. The design of the proposed 6-bus testing system is presented in Section III. Section IV shows the simulation results by using mainly DIgSILENT ${ }^{\circledR}$ and MATLAB ${ }^{\circledR}$ environments. Finally, the discussion and the conclusion are presented in Section V.

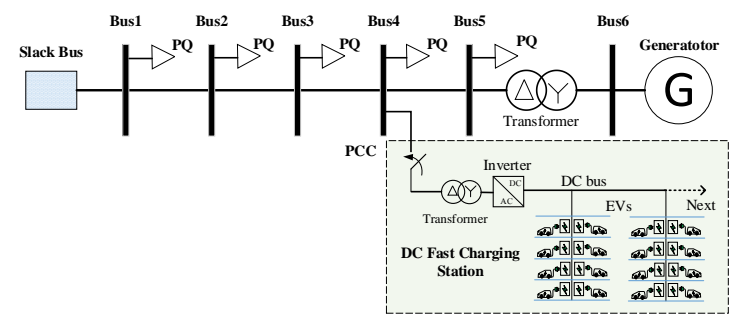

Fig. 2. The 6-bus testing system

\section{Power System Stability and EVs Load}

\section{II.1. Power System Swing}

The power system stability is presented using the mechanical torque and the electrical torque effects of the rotor generator in the transient state of the system, low power oscillatory, such as the occurrence of various types of faults and changed loads. This could result in dynamic changes in the rotor speed of the generator related to the acceleration torque. When the system is in average condition, it is balanced when the torque equals the electric torque, as shown in (1):

$$
T_{e}=T_{m}
$$

when the system is disturbed in various cases, it will cause $T_{e} \neq T_{m}$ to accelerate the rotor torque (accelerating torque $T_{a}$ ). The relationship between the acceleration torque and the moment of inertia of the generator is presented in Eqs. (2) and (3) [18]:

$$
\begin{gathered}
T_{a}=T_{m}-T_{e} \\
J \frac{d^{2} \theta_{m}}{d t^{2}} T_{a}=T_{m}-T_{e}
\end{gathered}
$$

The change in the mechanical torque is related to the moment of initial inertia $(J)$ of the mechanical torque angle and the acceleration torque versus time or the retarding torque for the system returning to its equilibrium state. The operation time of the electrical power system should be appropriately measured with the appropriate torque for the desired outcome of the optimal control of the grid.

\section{II.2. Power System Stabilizer (PSS)}

The PSS is used to stabilize the power system. The shaft speed is measured in terms of the frequencyvarying rotor speed or PSS signaling where any change in the output of the generator is detected. The control of the rotor's oscillation is done by using a signal to the Automatic Voltage Regulator (AVR) and the exciting field current of the generator [19]. Fig. 3 shows the PSS used for power system stability improvement from the system perturbation. The PSS is an additional part of the generator control scheme, which is very important for correcting the balance of the instability of the power system. The controlled activation has improved the electrical system in dynamic conditions and compensated for the power system oscillations.

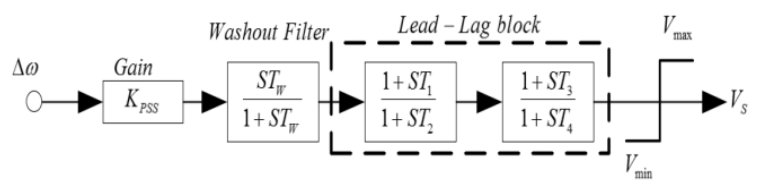

Fig. 3. Schematic diagram of the PSS 
This article has adapted the PSO in order to find the gain with lead-lag block control.

\section{II.3. Determination of Particles Size}

The PSO technique has been applied to find the PSS parameters.

The PSO has been represented by moving the swarm in order to find the food based on the crow hunting concept.

Randomized population groups and the use of population change evaluation have been chosen to record the results.

A mathematical model has been involved by using the velocity and enhancing the position of particles as presented in [20].

Therefore, the best position of the swarm has represented the optimal condition.

\section{II.4. The Electric Vehicles (EVs) Load Modeling}

This paper has presented the EVs model by using a polynomial or ZIP. ZIP is a type of VDL depending on the voltage variation in the bus. In addition, the EVs parameter can be expressed as represented in Eqs. (4) and (5) when a three-phase balanced load model has been considered as follows:

$$
\begin{aligned}
P & =P_{0}\left(a P\left(\frac{v}{v_{0}}\right)^{0}+b P\left(\frac{v}{v_{0}}\right)^{1}+\right. \\
& \left.+(1-a P-b P)\left(\frac{v}{v_{0}}\right)^{2}\right) \\
Q & =Q_{0}\left(a Q\left(\frac{v}{v_{0}}\right)^{0}+b Q\left(\frac{v}{v_{0}}\right)^{1}+\right. \\
& \left.+(1-a Q-b Q)\left(\frac{v}{v_{0}}\right)^{2}\right)
\end{aligned}
$$

where $1-a P-b P=c P, 1-a Q-b Q=c Q$, and $P, Q$ represent the reactive and the active electric power in each part. $V_{0}$ and $V$ are represented by nominal voltage and operation voltage applied to the right conditions, respectively. The EVs coefficient values of Eqs. (4) and (5) are presented in Table I.

\section{II.5. The Damping Ratio of the Electrical Power System}

The perturbation of the electrical power system in each case is affected by the low- and high-power oscillation.

The swing equation is related to mechanical torque and electrical torque directly affecting the speed and the frequency response of the rotation machine.
TABLE I

PARAMETERS OF EVS

\begin{tabular}{cc}
\hline \hline $\begin{array}{c}\text { ZIP Active and Reactive } \\
\text { Parameters }\end{array}$ & $\begin{array}{c}\text { Computer Simulations of a Typical } \\
\text { Charging System }\end{array}$ \\
\hline$a P$ & -0.1773 \\
$b P$ & 0.9949 \\
$c P$ & 0.1824 \\
$a Q$ & 4.993 \\
$b Q$ & -12.910 \\
$c Q$ & 8.917 \\
\hline \hline
\end{tabular}

Therefore, the power system oscillation will be related to the system characteristics with time in the specificity mode, which can be expressed as Equation (6):

$$
\lambda=\sigma \pm j \omega
$$

where $\sigma$ and $\omega$ are the written composition of the damping and frequency values, respectfully. In the swing of the power system, specific values have been chosen.

The frequency of swing of $f$ could be replaced by $f=\frac{\omega}{2 \pi}$ and with the composition of values. Damping can be computed by $\varsigma=\frac{-\sigma}{\sqrt{\sigma^{2}+\omega^{2}}}$. If the system has much damping, it will evolve faster. On the other hand, if there is less system damping rebounding into a balanced state of the system. This would be detrimental to the power system's stability.

\section{Design of Testing System with EVs Loads}

This paper has considered the large scale EVs penetration in the electrical power system. Therefore, the testing system has been represented by using a Single Machine Infinite Bus (SMIB) concept. An extended six bus of the grid has been used to solve the impact of the EVs on the grid. The EVs have been connected to bus No. B3. The transmission line distance between the buses has been defined as $10 \mathrm{~km}$. The testing system is presented in Fig. 2 in order to show the balanced load system. Meanwhile, the number of EVs has increased by $50 \%, 100 \%, 150 \%, 200 \%$, and $300 \%$ by using the ZIP modeling. The EVs have been defined by the active power of $20 \mathrm{MW}$ pf. 0.95 . The PQ loads of the grid have been defined by the active power of $50 \mathrm{MW}$, and the reactive power of $10 \mathrm{MVar}$. Meanwhile, the transmission line parameters have been defined by $R=0.0529$ $\Omega / \mathrm{km} /$ phase, $\quad X=0.529 \Omega / \mathrm{km} /$ phase, $\quad B=0.308129$ $\mu \mathrm{S} / \mathrm{km} /$ phase. The parameters of the EVs in ZIP modelling are presented in Table I. Therefore, the experiment process has been divided into three cases as follows:

- Case A: Testing System without PSS control;

- Case B: Testing System with PSS control;

- Case C: Testing system with PSS control and parameter turning when EVs were installed.

The objective function could be expressed as (7): 


$$
\max (J)=\max \left(\min \left(\left\{\varsigma_{i}\right\}\right)\right) \quad i=1,2,3 \ldots
$$

It has been determined by the value of the set of the maximum damping ratio function $(\zeta)$. It has represented the moment of inertia $(j)$ in the grids. The parameters from the PSS have been combined by controlling and compensating throughout the optimal parameters. The testing has been conducted using the PSO through the MATLAB $^{\circledR}$ program. The PSO can be defined by the parameters and the boundary, as shown in Table II.

The determined values of PSS parameters have been related to the PSO by defining the boundary. The values of the PSS configuration field could be expressed as $K=K_{L}+\left(K_{U^{-}} K_{L}\right) \times \operatorname{rand}()$ used for gain, value, and $T_{x}=T_{L}+\left(T_{U}-T_{L}\right) \times \operatorname{rand}()$, in order to find out the parameters, washout filter with lead-lag block, respectively [15].

The experimental process has been integrated with the DIgSILENT $^{\circledR}$ and MATLAB $^{\circledR}$ environments via MSExcel.

The data exchange from that software is composed of paralleling process. The results have been recorded as particles, rounds searching for the best answers, and sequences shown in Fig. 4 [19], [20].

TABLE II

PARAMETERS OF PSO FOR TURNING THE PSS

\begin{tabular}{cc}
\hline \hline Parameters & Value \\
\hline Number variable $\left(K_{P S S}, T_{1}, T_{2}, T_{3}, T_{4}\right)$ & 5 \\
The time constant of the washout filter $\left(T_{W}\right)$ & 10 \\
Weight of velocity of particle swarm $\left(c_{1}, c_{2}\right)$ & 2,2 \\
Time constant upper-lower value $\left(T_{U}, T_{L}\right)$ & $0.1,10$ \\
Gain constant upper-lower value $\left(K_{U}, K_{L}\right)$ & $0.1,100$ \\
Particle number $(N)$ & 25 \\
Maximum iteration $(i)$ & 100 \\
\hline \hline
\end{tabular}

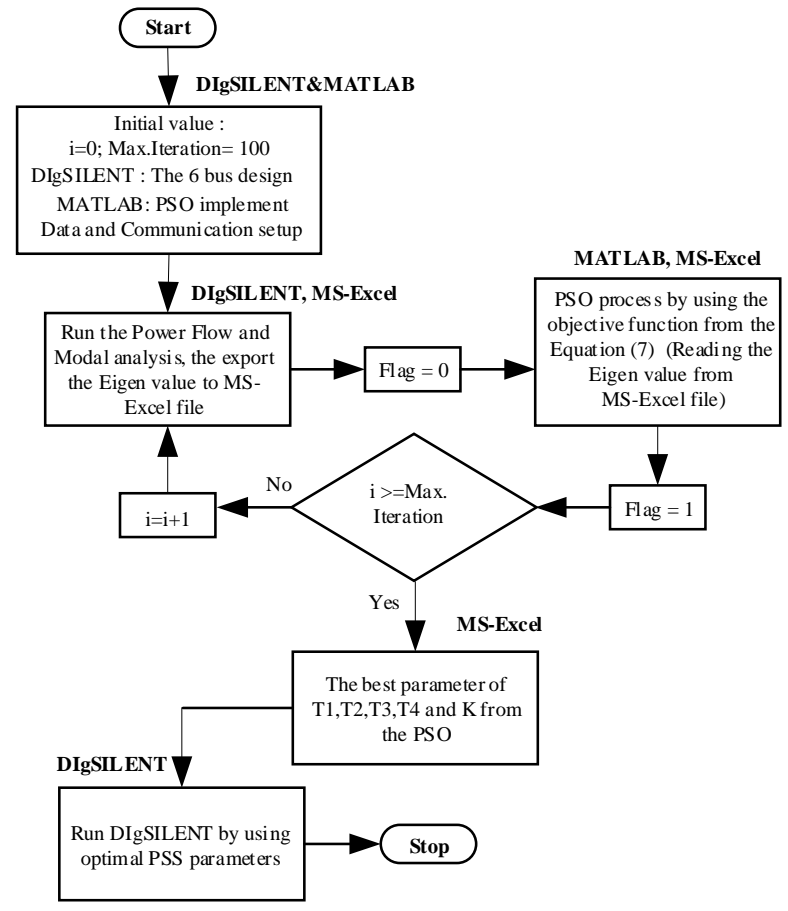

Fig. 4. Optimal parameter tuning for PSS by using the PSO
Fig. 4 shows the algorithm for finding the optimal parameters of the PSS by using the PSO. The flag in and the MS-Excel are controlled and have exchanged data from the simulated process, respectively. The end of the process has been extracted by the optimal damping ratio and the rotor angle by the DIgSILENT ${ }^{\circledR}[21]$.

\section{Simulation Results}

The PSO has computed the optimal PSS parameters and the frequency oscillation based on the dumpling ratio from case 3. A high penetration of the EVs is needed to adjust the PSS parameters in optimal conditions. The study from cases A and B has been used to compare the efficiency from the optimal PSS parameters of PSO by using the time step at $2 \mathrm{~s}$ of each EVs penetration. The optimal parameter of the PSS can be found in Table III.

The results are given in Table III and are graphically shown in Fig. 5 to Fig. 9 for oscillating the rotor. In the case $\mathrm{B}$, the parameters of the PSS have been defined by the original values from the DIgSILENT ${ }^{\circledR}$. Meanwhile, the parameters of each case of $\mathrm{C}$ have been delivered from the PSO process. The effect of the EVs has presented the different parameters of the PSS. Therefore, real-time simulation data of the energy management has needed quick response time and feedback to the control system. The optimal parameter needs to adjust and to be adapted in order to control the perturbation condition.

Therefore, the power system operation requires intelligence control in order to modify the control conditions.

Hence, the results of the optimal parameter from Table III could be described by the eigenvalues.

The frequency of swing and damping ratio has presented the power system stability from the converse of rotor oscillation. The comparison of the frequency of swing and the damping ratio is shown in Table III. Table IV shows the test results by comparing the optimal parameters. The rotor's swing frequency and the damping ratio have changed from the base cases when the optimal parameter from the PSO has been used.

TABLE III

PARAMETERS OF THE PSS FOR GENERATOR

\begin{tabular}{|c|c|c|c|c|c|c|}
\hline Parameter & $\bar{K}$ & $\overline{T_{W}}$ & $\bar{T} T_{1}$ & $\overline{T T_{2}}$ & $\bar{T} T_{3}$ & $\bar{T} T_{4}$ \\
\hline $\begin{array}{c}\text { Case B } \\
\text { Conventional } \\
\text { PSS }\end{array}$ & 50 & 10 & 3 & 0.3 & 2 & 0.2 \\
\hline $\begin{array}{c}\text { Case C } \\
\text { Optimal PSS } \\
\text { @ EV=50\% } \\
\text { Case C }\end{array}$ & 40.6730 & 10 & 0.7713 & 0.5407 & 1.8759 & 0.3835 \\
\hline $\begin{array}{c}\text { Optimal PSS } \\
\text { @ EV=100\% } \\
\text { Case C }\end{array}$ & 43.1570 & 10 & 2.2328 & 0.3853 & 2.5813 & 2.4263 \\
\hline $\begin{array}{c}\text { Optimal PSS } \\
\text { @ EV=150\% } \\
\text { Case C }\end{array}$ & 40.1670 & 10 & 2.7207 & 1.9014 & 1.8903 & 0.3936 \\
\hline $\begin{array}{c}\text { Optimal PSS } \\
\text { @ EV=200\% } \\
\text { Case C }\end{array}$ & 33.3690 & 10 & 1.0707 & 0.3839 & 1.3691 & 0.4564 \\
\hline $\begin{array}{l}\text { Optimal PSS } \\
\text { @ EV=300\% }\end{array}$ & 31.1770 & 10 & 1.4276 & 1.8664 & 2.8448 & 0.2786 \\
\hline
\end{tabular}


TABLE IV

ROTOR SWING FREQUENCY AND DAMPING RATIO

\begin{tabular}{cccc}
\hline \hline Test Case & $\begin{array}{c}\text { Specific } \\
\text { Eigenvalues }\end{array}$ & $\begin{array}{c}\text { Frequency of } \\
\text { swing (Hz) }\end{array}$ & $\begin{array}{c}\text { Damping } \\
\text { Ratio }\end{array}$ \\
\hline $\begin{array}{c}\text { O } \% \\
\text { Case A No PSS+ EVs= }\end{array}$ & $-0.5861 \pm \mathrm{j} 0.5861$ & 0.8885 & 0.1044 \\
$\begin{array}{c}\text { Case B Conventional } \\
\text { PSS+ EVs=0\% }\end{array}$ & $-18.9776 \pm \mathrm{j} 7.7063$ & 0.8945 & 0.1103 \\
$\begin{array}{c}\text { Case C Optimal PSS } \\
\text { @ EVs=50\% }\end{array}$ & $-2.6256 \pm \mathrm{j} 6.2479$ & 1.2265 & 0.9265 \\
$\begin{array}{c}\text { Case C Optimal PSS } \\
\quad \text { @ EVs=100\% }\end{array}$ & $-2.3902 \pm \mathrm{j} 6.3131$ & 1.0047 & 0.3540 \\
$\begin{array}{c}\text { Case C Optimal PSS } \\
\text { @ EVs=150\% }\end{array}$ & $-2.4658 \pm \mathrm{j} 6.3616$ & 1.0124 & 0.3614 \\
$\begin{array}{c}\text { Case C Optimal PSS } \\
\quad \text { @ EVs=200\% }\end{array}$ & $-2.7061 \pm \mathrm{j} 6.0493$ & 0.9627 & 0.4083 \\
$\begin{array}{c}\text { Case C Optimal PSS } \\
\text { @ EVs=300\% }\end{array}$ & $-2.2987 \pm \mathrm{j} 5.9175$ & 0.9418 & 0.3621 \\
\hline \hline
\end{tabular}

There is a relationship in each case caused by loading and perturbation of the electrical power system. The benchmarking of the simulation results has been presented by indicating the low-frequency oscillation and the damping ratio values. The frequency of swing from the EVs load perturbation level has been revealed in case $\mathrm{B}(\mathrm{EVs}=0 \%)$, case $\mathrm{C}$ at $\mathrm{EVs}$ of $50 \%, 100 \%$ and $150 \%$ by presenting in a local mode oscillation (1-3 Hz).

Meanwhile, in cases A, B, and C of $200 \%$ and $300 \%$, the EVs has been revealed by an inter-area mode (less than $1 \mathrm{~Hz}$ ). The optimal parameters of the PSS could increase the damping ratio and reduce the frequency of swin as shown in Fig. 5 to Fig. 9. Fig. 5 shows the rotation of rotor speed of each case when EVs perturbation level was at $2 \mathrm{~s}$ of $50 \%$. The optimal parameters of the PSS have been presented as significantly reducing the low frequency oscillatory by about $1.2265 \mathrm{~Hz}$ and short-time response for the rotor stability to within 5.592 s. Fig. 6 shows the rotation of rotor speed of each case when EVs perturbation level has been at $2 \mathrm{~s}$ of $100 \%$. Therefore, the optimal parameters of the PSS have been revealed in order to reduce the low frequency oscillatory by about $1.0047 \mathrm{~Hz}$, short-time response for the rotor stability to within $5.652 \mathrm{~s}$ and to a damping ratio of 0.3540 . Fig. 7 shows the rotation of rotor speed of each case when EVs perturbation level has been at $2 \mathrm{~s}$ of $150 \%$.

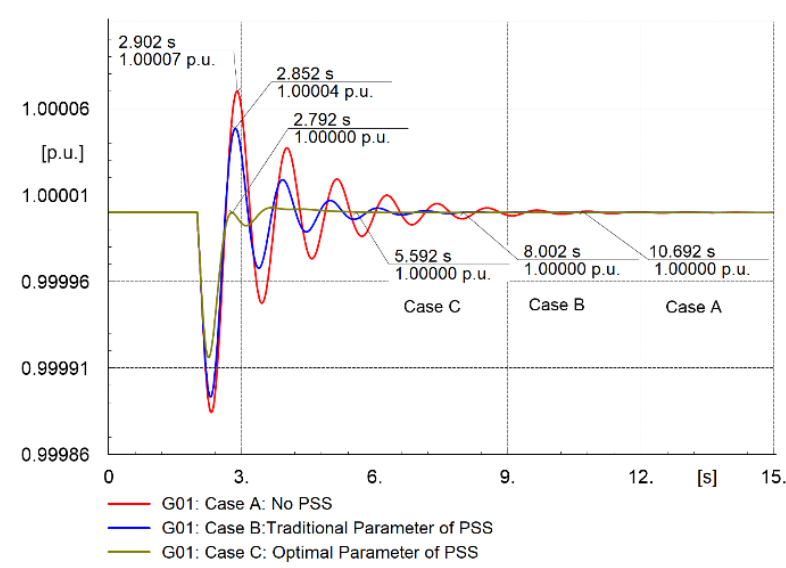

Fig. 5. Rotation of rotor speed of cases $\mathrm{A}, \mathrm{B}$, and $\mathrm{C}(\mathrm{EV}=50 \%)$

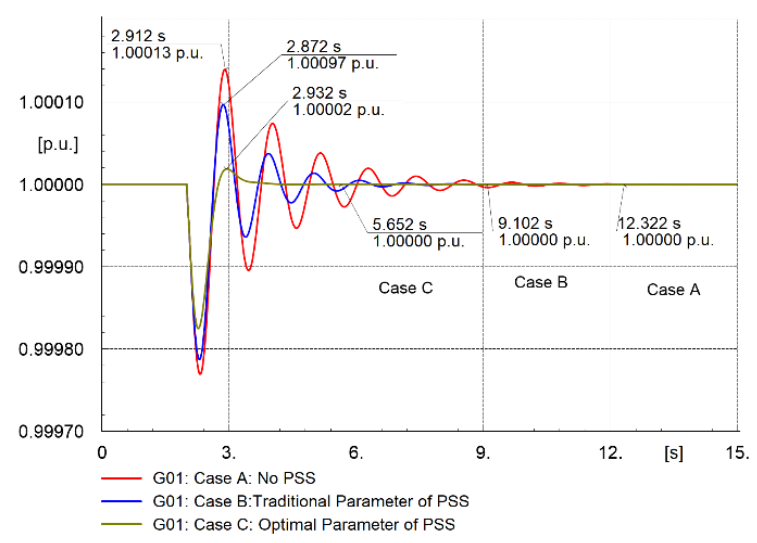

Fig. 6. Rotation of rotor speed of cases $A, B$, and C $(E V=100 \%)$.

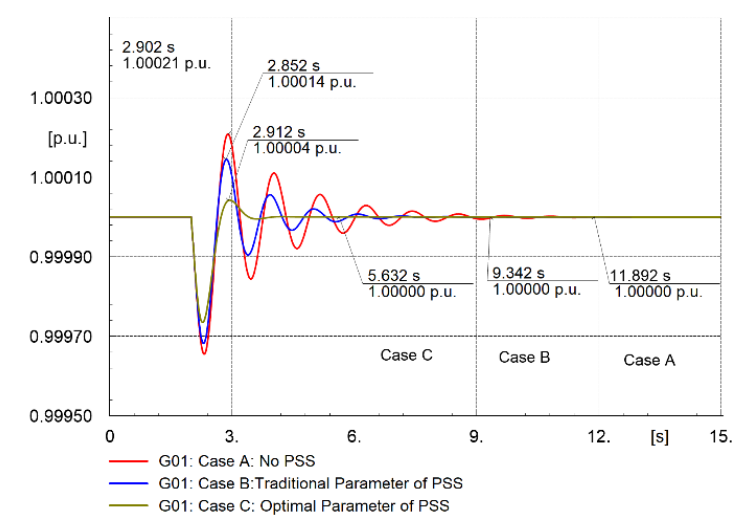

Fig. 7. Rotation of rotor speed of cases A, B, and C $(\mathrm{EV}=150 \%)$

The optimal parameters of the PSS have been presented as having reduced the low frequency oscillatory by about $1.0124 \mathrm{~Hz}$, short-time response for the rotor stability to within $5.632 \mathrm{~s}$, and to a damping ratio of 0.3614 . Fig. 8 shows the rotation of rotor speed of each case when EVs perturbation level has been at $2 \mathrm{~s}$ of $200 \%$. The optimal parameters of the PSS have been presented in order to reduce the low frequency oscillatory by about $0.9627 \mathrm{~Hz}$, short-time response for the rotor stability to within $5.652 \mathrm{~s}$, and to a damping ratio of 0.4083 . The high damping ratio value revealed could reduce the frequency of swing rotor from cases $\mathrm{A}, \mathrm{B}$ and part of case $\mathrm{C}$, not covering the case $\mathrm{C}$ under EVs of $300 \%$.

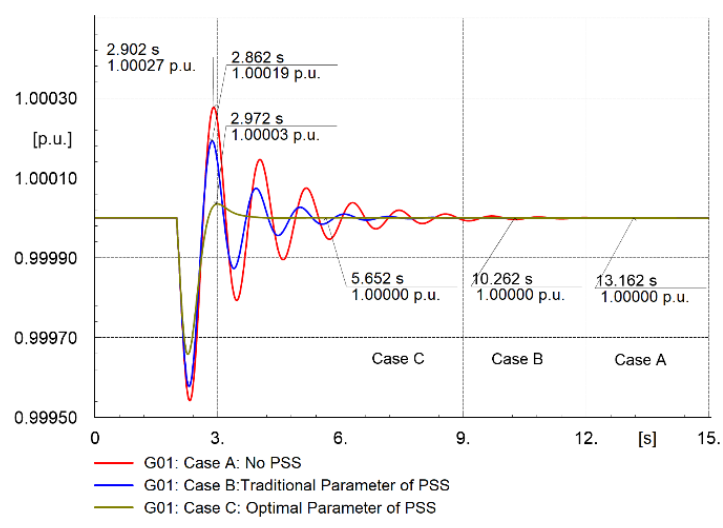

Fig. 8. Rotation of rotor speed cases A, B, C respectively $(\mathrm{EV}=200 \%)$ 


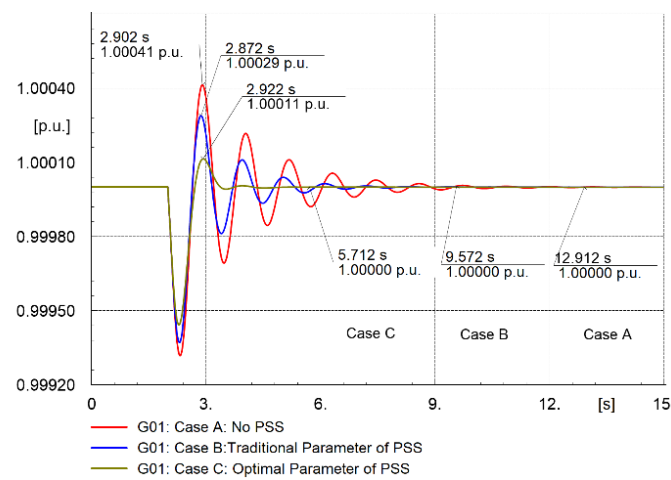

Fig. 9. Rotation of rotor speed of cases A, B, and C $(E V=300 \%)$

Fig. 9 shows the rotation of rotor speed of each case when EVs perturbation level has been at $2 \mathrm{~s}$ of $300 \%$.

The optimal parameters of the PSS have been showed to reduce the low frequency oscillatory by about 0.9418 $\mathrm{Hz}$, short-time response for the rotor stability to 1 p.u. within $5.712 \mathrm{~s}$, and a damping ratio of 0.3621 . The rotor oscillation of the generator from each case could reach the equilibrium state, but it has depended on the power system component and has installed the PSS. Therefore, the PSS control can reduce the time response and the low-frequency oscillation. The damping ratio can be used to analyze the optimal condition of the PSS based on the Eigenvalue. The optimal parameters of the PSS by using the PSO could improve the system oscillation. The yield of the PSS could reach the equilibrium point for reducing the rotor oscillation. Therefore, the generator racks of the optimal control may have increased the instability level of the grid.

\section{Conclusion}

The results of this paper have indicated an optimal parameter control of the PSS in six bus-testing systems under different EVs penetration levels. The EVs load modeling has been represented by ZIP load modeling and has been integrated into the electrical power system. The PSO techniques for turning PSS parameters can be adapted to control the low-frequency oscillation of the grid. This paper succeeds in the optimal PSS control via the Eigenvalues by communication between DIgSILENT $^{\circledR}$ and MATLAB ${ }^{\circledR}$. This methodology could reduce the time response to an equilibrium state of 1.00000 p.u. of the EVs $50 \%, 100 \%, 150 \%, 200 \%$, and $300 \%$ by $5.592 \mathrm{~s}, 5.652 \mathrm{~s}, 5.632 \mathrm{~s}$, and $5.652 \mathrm{~s}$, respectively. Therefore, high penetration level of EVs and load change could reduce the impact of the lowfrequency oscillation by using the optimal parameter turning of the PSS. The grid could improve the power system stability on the dynamic control by using this purpose.

\section{Acknowledgments}

The research team would like to express our sincere gratitude to the "Provincial Electricity Authority (PEA)" for the support in the experimental of this research paper.

\section{References}

[1] Y. Kongjeen and K. Bhumkittipich, Modeling of electric vehicle loads for power flow analysis, based on PSAT, in Proc. the 13th International Conference on Electrical Engineering/Electronics, Computer, Telecommunications and Information Technology (ECTICON), Chiang Mai, Thailand, Sep. 2016, pp.1-6.

[2] A. Purwadi, N.Shani, N.Heryana, T.Hardimasyar, M. Firemansyah and Arrester SR. Modelling and Analysis of Electric Vehicle DC fast charging Infrastructure Based on PSIM, In Proc. the 2013 First International Conference on Artificial Intelligence, Modelling and Simulation, 2013, pp.1-6.

[3] C. H. Dharmakeerthi, N. Mithulananthan, T.K. Saha, Impact of Electric Vehicle Load on Power System Oscillatory Stability, International Journal of Electrical Power and Power Energy System, vol. 57, pp. 241-249, May 2014.

[4] S. Izadkhast, P. Garcia-Gonzalez, and P. Frías, An Aggregate Model of Plug-In Electric Vehicles for Primary Frequency Control, IEEE Transactions on Power Systems, vol.30, pp.1475 1482, Aug. 2015.

[5] F. Geth, N. Leemput, J. Van Roy, J. Büscher, R. Ponnett,e, and J. Driesen, Voltage droop charging of electric vehicles in a residential distribution feeder, in Proc.2012 3rd IEEE PES Innovative Smart Grid Technologies Europe (ISGT Europe), Berlin, Germany, Feb. 2013,p p.1-8.

[6] F. Milano and O. Hersent, Optimal Load Management with Inclusion of Electric Vehicles and Distributed Energy Resources, IEEE Transactions on Smart Grid, vol.5, pp. 662 - 672, March 2014.

[7] H. Turker, S. Bacha, D. Chatroux and A. Hably, Aging rate of low voltage transformer for a high penetration of Plug-in Hybrid Electric Vehicles (PHEVs), in Proc. 2012 IEEE PES Innovative Smart Grid Technologies (ISGT), Washington, DC, USA, April 2012, pp. 1 - 8 .

[8] S. Panich and J.G. Singh, Impact of plug-in electric vehicles on voltage unbalance in distribution systems, International Journal of Engineering, Science and Technology, vol.7, no.3, pp.76-93, 2015. doi: http://dx.doi.org/10.4314/ijest.v7i3.10S

[9] H. Turker, S. Bacha, D. Chatroux and A. Hably, Low-Voltage Transformer Loss-of-Life Assessments for a High Penetration of Plug-In Hybrid Electric Vehicles (PHEVs), IEEE Transactions on Power Delivery, vol. 27, pp. 1323 - 1331, July 2012.

[10] P. Kundur, Power System Stability and Control, McGraw-Hill: New York, pp. 272-273, 1994

[11] A. Jimenez and N. García, Power flow modeling and analysis of voltage source converter-based plug-in electric vehicles, In Proc. 2011 IEEE Power and Energy Society General Meeting, Detroit, MI, USA, July 2011, pp.1-6.

[12] A.M. A. Haidar and K.M. Muttaqi, Behavioral Characterization of Electric Vehicle Charging Loads in a Distribution Power Grid through Modeling of Battery Chargers, IEEE Transactions on Industry Applications, vol.52, pp 483 - 492, Jan.-Feb.2016.

[13] Del Pizzo, A., Meo, S., Brando, G., Dannier, A., Ciancetta, F., An Energy Management Strategy for Fuel-cell Hybrid Electric Vehicles via Particle Swarm Optimization Approach, (2014) International Review on Modelling and Simulations (IREMOS), 7 (4), pp. 543-553.

doi: https://doi.org/10.15866/iremos.v7i4.4227

[14] Abidi, M., Fizazi, H., Boudali, N., Clustering of Remote Sensing Data Based on Spherical Evolution Algorithm, (2021) International Review of Aerospace Engineering (IREASE), 14 (2), pp. $72-79$. doi: https://doi.org/10.15866/irease.v14i2.19209

[15] Boukef, H., Benrejeb, M., Borne, P., Genetic Algorithm and Based Particle Swarm Optimization Comparison for Solving a Flow-Shop Multiobjective Scheduling Problem in Pharmaceutical Industries, (2018) International Journal on Engineering Applications (IREA), 6 (6), pp. 221-226. doi: https://doi.org/10.15866/irea.v6i6.17000

[16] Ali, H., Taha, A., Hasanien, H., Performance Improvement of 
Wind Generator Using Hybrid Particle Swarm Algorithm and Grey Wolf Optimizer, (2021) International Journal on Energy Conversion (IRECON), 9 (2), pp. 63-73.

doi: https://doi.org/10.15866/irecon.v9i2.20350

[17] Gunantara, N., Sudiarta, P., Antara, I., Multi-Criteria Weights on Ad Hoc Networks Using Particle Swarm Optimization for Optimal Path Pairs, (2018) International Review of Electrical Engineering (IREE), 13 (1), pp. 15-22. doi: https://doi.org/10.15866/iree.v13i1.14082

[18] A. Aonklang and K. Bhumkittipich Low-Frequency Oscillation Compensation in Power System with the Flexible Power Controller, In Proc. the 5th Rajamangala University of Technology National Conference RMUTP Research Journal Special Issue, pp.51-60, 2013.

[19] S. Phasuk, K. Buanchai, and T. Kerdchuen, Proper Installation of AVR in Primary Distribution System with PSO, In Proc. the 5th Electrical Engineering Network (EENET 2013), Prachuap Khiri Khan, Thailand, Mar. 2012, pp.1-4.

[20] A. Stativa, M. Gavrilas, A metaheuristic approach for power system stability enhancement, In Proc. World energy system conference-WESC, Aug. 2012, pp.483-488.

[21] DIgSILENT ${ }^{\circledR}$ PowerFactory manual 2020b.

\section{Authors' information}

${ }^{1}$ Electrical Engineering Department, Engineering School, RMUTT, Thanyaburi, Pathum Thani, 12110, Thailand.

${ }^{2}$ Electrical Engineering Department, RMUTI, Nakornrachasima, 30000, Thailand.

${ }^{3}$ CNTEE Transelectrica, Romania.

${ }^{4}$ University of Queensland, Brisbane, Australia.

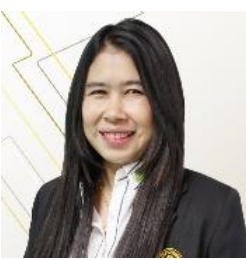

Kulsomsup Yenchamchalit received a B.Sc. degree in Electrical Industrial Technology at Thepsatri Rajabhat Institute, Lopburi, Thailand and M.Eng. in Electrical Engineering at Mahanakorn University of Technology (MUT), Bangkok, Thailand. Currently, she is a doctoral student at Rajamangala University of Technology Thanyaburi (RMUTT), Pathum Thani, Thailand. Her research interest is in power system stability and optimization technique in electrical power systems.

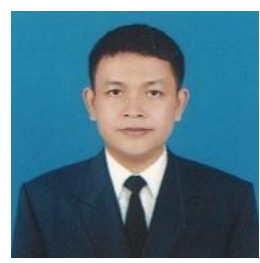

Yuttana Kongjeen received B.Eng. degree and M.Eng. degree in Electrical Engineering from Rajamangala University of Technology Isan (RMUTI), Nakhonratchasima, Thailand in 2000 and 2005, respectively. He also obtained a D.Eng. degree in Electrical Engineering from Rajamangala University of Technology Thanyaburi (RMUTT), Pathum Thani, Thailand, in 2018. His research interests are power system optimization techniques, energy storage systems, power system stability, and renewable energy integration system.

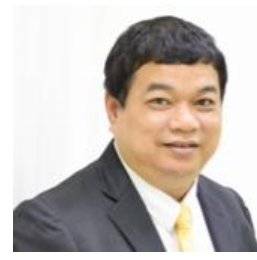

Krischonme Bhumkittipich (Corresponding Author) received a B.Eng. degree in Electrical Power Engineering from Rajamangala Institute of Technology (RIT), Pathum Thani, Thailand in 1997, a M.Eng. degree in Electrical Engineering from Chulalongkorn University, Bangkok, Thailand in 2000, and a D.Eng. degree in Energy from Asian Institute of Technology, Pathum Thani, Thailand, in 2008. From 2002-2004, he worked as a research associate at the Institute of Power Electronics and Electrical Drives (ISEA), RWTH-Aachen University, Aachen, NRW, Germany. He is currently an Associate Professor with the Department of Electrical Engineering, Faculty of Engineering, RMUTT. He is also the Vice President of Academic and Research Affairs at RMUTT, Pathum Thani, Thailand. He is a senior member of IEEE in 2015, an active member of IEEE Power \& Energy Society, IEEE Power Electronics Society, IEEE Industry Applications Society, IEEE Dielectrics and Electrical Insulation Society, and a member of the Institute of Electrical Engineering of Japan (IEEJ). He is on the board committee of the IEEE Power and Energy Society-Thailand chapter. His research interests are future electric power grids, power system dynamics and stability, power system interconnection, electric vehicle, smart mobility, analytical studies on the complexity of power systems, and future innovation for smart social life.

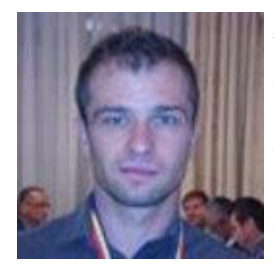

Andrei Stativa received his Ph.D. degree in electrical engineering from Gheorghe Asachi Technical University of lasi, Romania, in 2012, with an external practical stage of four months at TU Delft, Nederlands. He is an engineer at CNTEE Transelectrica, Romania. His research interests are in power system stability and optimization technique in electrical system systems.

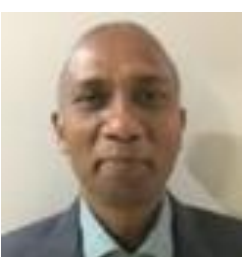

Nadarajah Mithulananthan was born in Sri Lanka. He received his Ph.D. from University of Waterloo, Canada in Electrical and Computer Engineering in 2002. He worked as an electrical engineer at Generation Planning Branch of Ceylon Electricity Board in Sri Lanka and as a research leader at Chulalongkorn University, Bangkok, Thailand. He is currently an associate professor at University of Queensland (UQ). He also served as the coordinator of energy field of study and director of regional energy resource information center (RERIC) at Asian Institute of Technology, Bangkok, Thailand. His main research interests are grid integration of renewable energy and energy storage systems. He is the Director of Research Training and Postgraduate Coordinator at the School of Information Technology and Electrical Engineering at UQ. 